\title{
The preparation and physical properties of polysulfide-based elastomers through one-pot thiol-ene click reaction
}

\author{
G. Z. Zhang, Z. K. Fan, Y. W. Quan", Q. M. Chen \\ Department of Polymer Science and Engineering, School of Chemistry and Chemical Engineering, State Key-Laboratory \\ of Coordination Chemistry, Nanjing University, 210093 Nanjing, P. R. China
}

Received 24 January 2013; accepted in revised form 18 March 2013

\begin{abstract}
In this paper, polysulfide-based elastomers were successfully prepared through a simple one-pot thiol-ene click reaction of the liquid polysulfide oligomer with bisphenol-A diacrylate resin. Real-time Fourier transform infrared spectroscopy (FTIR) analysis showed that the molecular weight of the liquid polysulfide oligomer had no effect on mercaptan functional group conversion. The obtained elastomers continued to keep low temperature flexibility of polysulfide except Elastomer-LP3, which was due to higher content of bisphenol-A structure. All the samples had a tensile strength of over 0.7 MPa, which was comparable to that of polysulfide polymer cured by metal oxide. Moreover, the samples exhibited higher thermal stability than metal oxide cured polysulfide. This vulcanization methodology will provide a fast, efficient, and environmentally friendly approach (without metal oxides and plasticizers) for preparing polysulfide elastomers.
\end{abstract}

Keywords: mechanical properties, liquid polysulfide, elastomer, click reaction

\section{Introduction}

During the last few years, thiol-ene coupling reaction has become a subject of intense study in various areas of science and engineering [1-4]. This reaction, whether proceeding by a free-radical reaction or Michael addition, carries many of the attributes of click reactions as follows: (a) high yields with minimal byproducts, (b) insensitive to ambient oxygen or water, (c) region or stereospecificity, (d) proceeds under mild, solventless reaction conditions. Up to now, thiol-ene chemistry has been effectively applied in a wide range of disciplines, ranging from surface modification [5-6], polymer functionalization [7-9], photolithography and microdevice fabrication [10], high-energy absorbing materials [11-12], applications in biomaterias [13], organic functionalization [14-15], and so on.

Usually, there are four low-molecular-weight thiols typically encountered in literatures, including thio- phenols [16-17], thiol propionates [5, 7, 10-12], alkyl thiols [7-8] and thiol glycolates [7, 14]. In recent years, some new oligomeric thiols have been synthesized and incorporated into thiol-ene networks, which opens up new applications or provides improved properties. For example, the synthesis of dithiol polyester and its incorporation into thio-ene networks brings a new opportunity for creating semicrystalline networks [18-19]. The use of oligomeric thiols has the distinct advantage of low shrinkage and a reduction in stress during the photopolymerization process [20] or lower glass transition temperatures and more uniform networks [21]. In other work, thiocarbamate oligomers are synthesized to prepare photocured/thermal cured films with high glass transition temperature, excellent hardness and impact values [22].

The present investigation also extends thiol-ene click reaction to a long chain liquid polysulfide (PSF)

\footnotetext{
${ }^{*}$ Corresponding author, e-mail: quanyiwu@nju.edu.cn (C) BME-PT
} 
oligomer containing terminal thiol groups. Traditionally, the main curing agents for PSF oligomers are metal oxides and other metal oxy-salts, which make use of the reducing properties of the thiol group to cause cross-linking [23]. These cross-linked elastomers derived from PSF oligomers have high resistance to UV radiation and the environment, exhibit good low-temperature properties, low water-vapour transmission, and resist solvents and chemicals. Our earlier works have also studied metal oxide or isocyanate cured polysulfide polymer [24-26] and explore kinetic analysis of polysulfide-acrylate click reaction by dielectric analyzer and dynamic mechanical analyzer [27]. Here, we successfully prepared polysulfide-based elastomers by reacting PSF oligomers with bisphenol-A diacrylate resin through one-pot thiol-Michael addition reaction, in which tris(dimethylaminomethyl)-phenol (DMP-30) was used as a catalyst. The effect of molecular weight and cross-linking agent of PSF oligomers on mechanical and thermal properties of obtained elastomers was discussed in detail.

\section{Experimental}

\subsection{Materials and synthesis}

PSF oligomers were supplied by Thiokol Co. Japan (The main properties of the PSF oligomers are listed in Table 1). Bisphenol-A diacrylate resin (VR77, $\left.M_{\mathrm{n}}=510-600\right)$ was supplied by Shanghai Showa Highpolymer Co, Shanghai, China. Tris(dimethylamino-methyl)phenol (DMP-30) was commercially available material. All materials were used as received without further purification.

The polysulfide-based elastomers were prepared at the stoichiometric ratio of mercaptan/acrylate. PSF oligomers and bisphenol-A diacrylate resin were completely mixed with $2 \mathrm{wt} \%$ DMP- 30 by a mechanical stirrer at room temperature and degassed by a Siemens DAC 150FV high-speed mixer by 3000/min (Produced by Hauschild, Wuppertal-Cronenberg, Germany). Then the bubble-free mixture was poured onto the mold of PTFE, and cured at $23 \pm 2^{\circ} \mathrm{C}$ for 5 days.

\subsection{Instrumentation and characterization}

The ${ }^{1} \mathrm{H}$ NMR spectra of the samples were obtained on an AVANCE DPX-500 MHz spectrometer (Bruker, Fällanden, Switzerland) in $\mathrm{CDCl}_{3}$. Curing behavior of the PSF oligomer and bisphenol-A diacrylate resin was obtained using real-time infrared (RTIR) spectroscopy, which was recorded on a Vector 70 spectrometer (Bruker, Ettligen, Germany). The samples were coated on a $\mathrm{KBr}$ disk at $25^{\circ} \mathrm{C}$, and then, the RTIR spectra were collected at a resolution of 2 from $400 \sim 4000 \mathrm{~cm}^{-1}$ every $5 \mathrm{~min}$ (for LP3 system, the RTIR spectra was collected every $2 \mathrm{~min}$ in first 30 minutes) until no further change was observed in the spectra, and the peak at 2570 or $810 \mathrm{~cm}^{-1}$, was used to monitor $\mathrm{C}=\mathrm{C}-\mathrm{H}$ bending or $-\mathrm{SH}$ conversion respectively.

The extraction and swelling tests (HG/T 3870-2008 China) were performed on $20 \mathrm{~mm} \times 20 \mathrm{~mm} \times 2 \mathrm{~mm}$ cut specimen by the immersion method in toluene at $25^{\circ} \mathrm{C}$. Thereafter, the test specimen was taken out, blotted with a piece of filter paper, and weighed. After immersion, the samples were dried at $100^{\circ} \mathrm{C}$ in the vacuum oven for $24 \mathrm{~h}$. The mass of the specimen was measured by electronic digital balance with an accuracy of $0.001 \mathrm{~g}$. Each result was obtained by repeating the test with three specimens. The swelling ratio is defined as: $\mathrm{Q} \%=\left(M_{\mathrm{t}}-M_{0}\right) \cdot 100 / M_{0}$, where $M_{0}$ and $M_{\mathrm{t}}$ are the mass of the test piece before swelling and after immersion respectively. The gel fraction is defined as: Ti\% $=\left(M_{\mathrm{w}} / M_{0}\right) \cdot 100$, where $M_{0}$ is the mass of the test piece before immersion, and $M_{\mathrm{w}}$ is the mass of the dry sample after immersion.

Thermal stability of the polysulfide was characterized by Thermogravimetric Analysis (TG, STA 449 C, NETZSCH, Selb, Germany), at heating rate of $20^{\circ} \mathrm{C} / \mathrm{min}$ from 25 to $650^{\circ} \mathrm{C}$ under nitrogen. Dynamic thermal mechanical properties of the samples (tension model) were measured using a DMA-450 (Produced by 01 dB- Metravib Co., Limonest, France) with a frequency of $1 \mathrm{~Hz}$, and heating rate of $3{ }^{\circ} \mathrm{C} / \mathrm{min}$ from -70 to $+150^{\circ} \mathrm{C}$. The dimensions of the samples were $10 \mathrm{~mm} \times 15 \mathrm{~mm} \times 2 \mathrm{~mm}$. The tensile

Table 1. The main properties of liquid polysulfide oligomers

\begin{tabular}{|l|c|c|c|c|c|c|}
\hline \multicolumn{1}{|c|}{ Liquid polysulfide oligomers } & LP-3 & LP-23 & LP-980 & LP-2 & LP-32 & LP-55 \\
\hline Average molecular weight & 1000 & 2500 & 2500 & 4000 & 4000 & 4000 \\
\hline Cross-linking agent & 2 & $2 \%$ & $0.5 \%$ & $2 \%$ & $0.5 \%$ & $0.05 \%$ \\
\hline Mercaptan fraction (-SH) & $5.9-7.7 \%$ & $2.5-3.5 \%$ & $2.5-3.5 \%$ & $1.5-2.0 \%$ & $1.5-2.0 \%$ & $1.5-2.0 \%$ \\
\hline
\end{tabular}

*In the synthesis of liquid polysulfide oligomers, bis-2-chloroethyl formal is the usually used monomer and $0.05-4 \% 1,2,3$-trichloropropane is added as a cross-linking agent. 
properties of samples were measured on an Instron 4466 Universal Materials Testing Machine (produced by Instron Co., Norwood, MA, USA) with a speed of $200 \mathrm{~mm} / \mathrm{min}$ at $23^{\circ} \mathrm{C}$. The cured film in $2 \mathrm{~mm}$ thickness was cut into dumb-bell-shaped specimens. Each result was obtained by the test repetition with three specimens.

\section{Results and discussion}

\subsection{Synthesis and characterization}

The procedure for the preparation of polysulfidebased elastomers is outlined in Figure 1. This reaction was effectively catalyzed by a tertiary amine DMP-30. The dosage of catalyst was fixed to be $2 \mathrm{wt} \%$ of monomers. With more catalyst used, the operating time would be shortened extremely. Usually, this step-growth polymerization(polyaddition) gives linear polymer. However, the cross-linked elastomers are finally obtained due to the branching of PSF oligomers. The reason is that, in the synthe- sis of PSF oligomers, bis-2-chloroethyl formal is the usually used monomer and $0.05-4 \%$ 1,2,3-trichloropropane is added as a cross-linking agent, which produces some branched chains in PSF oligomers.

Figure 2 shows ${ }^{1} \mathrm{H}$ NMR spectra of the mixture of the PSF oligomer LP-55 and bisphenol-A diacrylate resin before and after Michael addition reaction (Here, in order to get soluble product for ${ }^{1} \mathrm{H}$ NMR analysis, the PSF oligomer with the lowest content of cross-linking agent, LP55 resin, was chosen. Furthermore, the reaction was carried out in the solution of $\mathrm{CDCl}_{3}$, and ${ }^{1} \mathrm{H} \mathrm{NMR}$ spectra was investigated before the deposition appeared). In Figure 2, the peaks at $6.18 \mathrm{ppm}$ (multiplet), $5.90 \mathrm{ppm}$ (doublet) and $6.47 \mathrm{ppm}$ (doublet) can be assigned to protons of $\mathrm{CH}_{2}=\mathrm{CHCOO}-\mathrm{R}$. After the thiol-Michael addition reaction, these characteristic peaks almost disappear in the spectrum (the residual double bond protons calculated from integration are about 5\%). Meanwhile, the new peaks around $3.0 \mathrm{ppm}$ attrib-

$$
\text { liquid polysulfide oligomer }
$$

Figure 1. The thiol-Michael addition reaction between the liquid polysulfide oligomer and bisphenol-A diacrylate resin

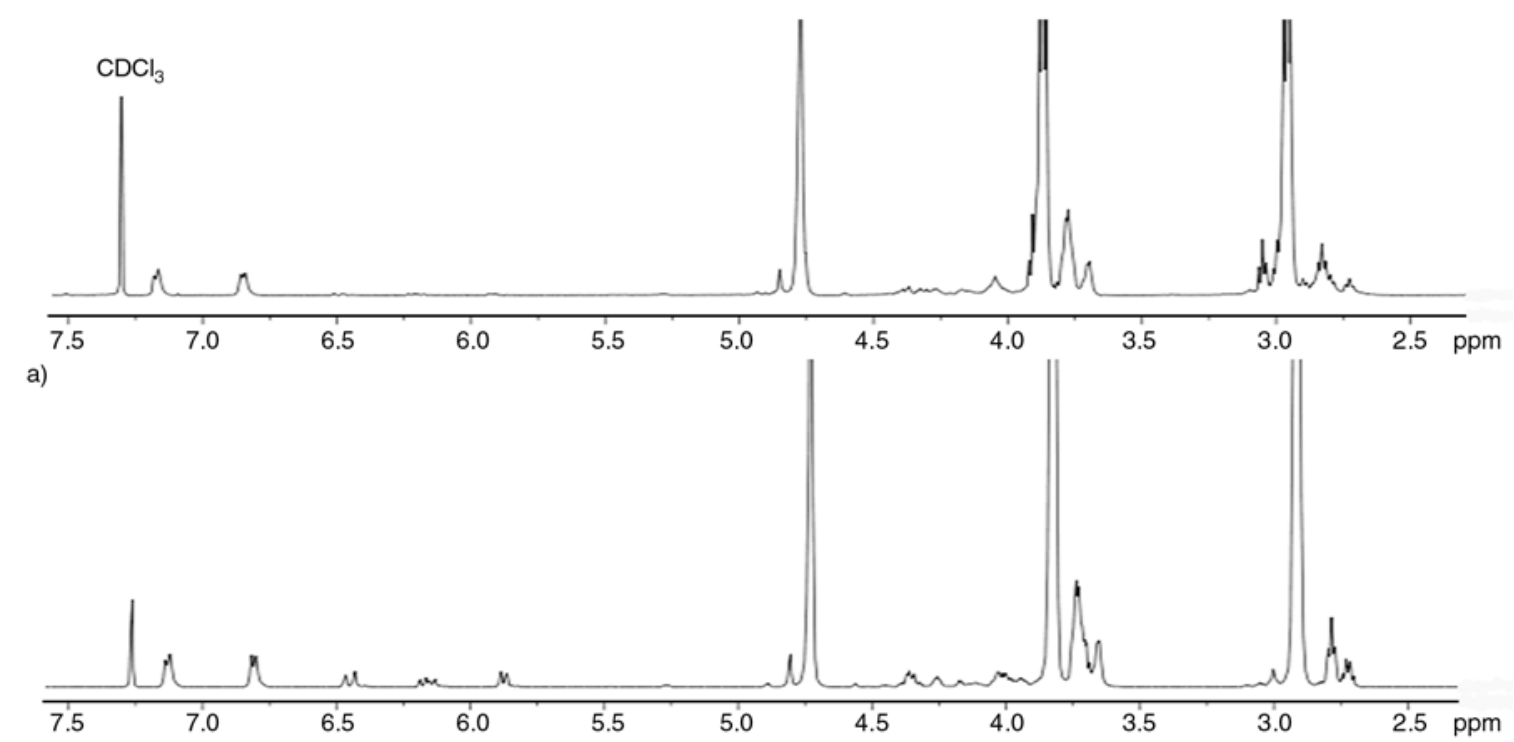

b)

Figure 2. ${ }^{1} \mathrm{H}$ NMR spectra of the mixture of the liquid polysulfide oligomer and bisphenol-A diacrylate resin before (b) and after (a) Michael addition 


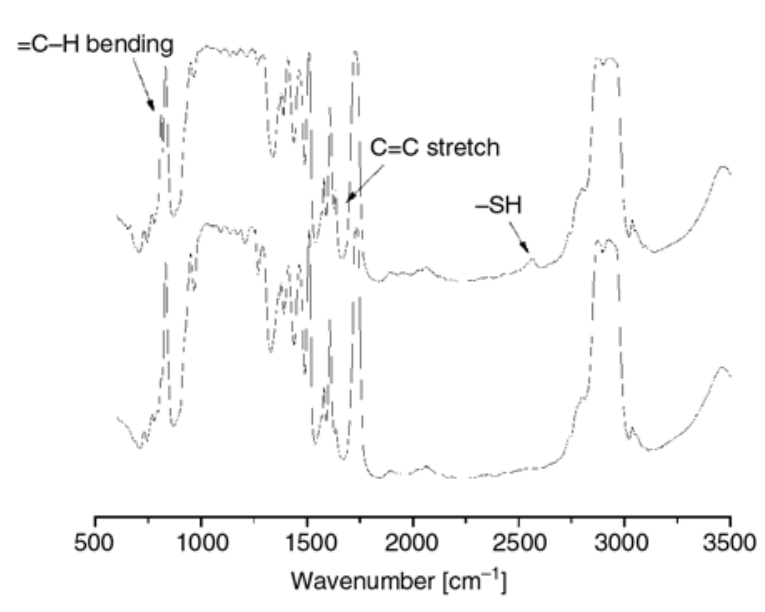

Figure 3. FTIR spectra of the mixture of the liquid polysulfide oligomer and bisphenol-A diacrylate resin before and after Michael addition reaction

uted to the protons of $\mathrm{SCH}_{2}-\mathrm{CH}_{2} \mathrm{COO}-\mathrm{R}$ appear. Furthermore, the IR spectra of the typical monomer mixture and the resulting elastomer are compared in Figure 3. The monomer mixture has absorption peaks at 1630 and $810 \mathrm{~cm}^{-1}$, attributed to $\mathrm{C}=\mathrm{C}$ stretching and $=\mathrm{C}-\mathrm{H}$ bending respectively, which is lacking in the obtained elastomer. The complete loss of thiol $\left(2570 \mathrm{~cm}^{-1}\right)$ in polysulfide resin also can be detected in IR spectra. All these results demonstrate that the essentially quantitative thiol-Michael addition reaction proceeded between the long chain PSF oligomer and bisphenol-A diacrylate resin.

In order to investigate the effect of molecular weight of PSF oligomers on the thiol-ene addition reaction, real-time infrared spectroscopy was used to monitor curing behavior of PSF oligomers and bisphenol-A diacrylate resin. Baseline correction and normalization were carried out by the OPUS software to eliminate the influence of transparency change during the curing process. Figure 4 illustrates the functional group conversions that were calculated according to the intensity change of the peaks $\left(2570 \mathrm{~cm}^{-1}\right)$ as described in the literature [28]. It shows that this

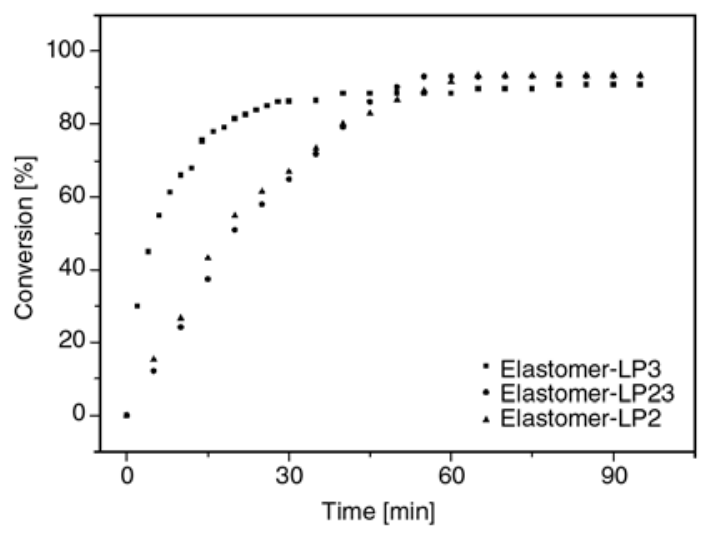

Figure 4. RTIR-based plot ( $\%$ conversion vs. time) of bisphenol-A diacrylate and liquid polysulfide oligomers with different molecular weight. Peak loss was measured at $2570 \mathrm{~cm}^{-1}$ for thiol conversion.

thiol-ene Michael addition was efficient with conversions of about $91 \%$ after 1 hour despite of different chain length of PSF oligomers, and the final conversion of all samples reached to $98 \%$ after reacting for $24 \mathrm{~h}$. However, the initial reaction rate changed with different molecular weight, it took only 5 min for Elastomer-LP3 to reach fifty percent conversion of SH group, but the difference of reaction rate between Elastomer-LP23 and ElastomerLP2 was relatively slight, which could be directly attributed to higher mercaptan fraction and lower viscosity of the PSF oligomer LP3.

Swelling tests on cured polysulfide-based elastomers were performed by the immersion method in toluene at $25^{\circ} \mathrm{C}$. The equilibrium of solvent absorption was established in $120 \mathrm{~h}$, with more immersion time, the weight did not increase any more for all specimens. The swelling percentage and gel fraction of elastomers after $120 \mathrm{~h}$ are outlined in Table 2. All of the samples used in this study had gel fractions around $90 \mathrm{wt} \%$ except for Elastomer-LP55, which was due to relatively lower cross-linking agent. This also indicated a nearly complete reaction of

Table 2. Gel fractions, swelling ratio, glass transition temperature and mechanical properties of Polysulfide-based elastomers

\begin{tabular}{|c|c|c|c|c|c|c|c|c|}
\hline Sample & $\begin{array}{c}\text { Weight } \\
\text { composition } \\
\text { of PSF/VR77 }\end{array}$ & $\begin{array}{c}\text { Containing of } \\
\text { polysulfide } \\
\text { blocks }[\%]^{*}\end{array}$ & $\begin{array}{c}\text { Gel fraction } \\
\text { Ti [\%] }\end{array}$ & $\begin{array}{c}\text { Swelling } \\
\text { ratio Q [\%] }\end{array}$ & $\mathbf{T}_{\mathbf{g}}\left[{ }^{\circ} \mathbf{C}\right]$ & $\begin{array}{c}\text { Tensile } \\
\text { strength } \\
\text { [MPa] }\end{array}$ & $\begin{array}{c}\text { Ultimate } \\
\text { elongation } \\
{[\%]}\end{array}$ & $\begin{array}{l}\text { Hardness } \\
\text { [Shore A] }\end{array}$ \\
\hline Elastomer-LP3 & $1.8: 1$ & 64.2 & 92.3 & 35.6 & -19.0 & 0.91 & 207 & 39 \\
\hline Elastomer-LP23 & $4.5: 1$ & 81.3 & 90.7 & 54.4 & -36.3 & 0.88 & 175 & 38 \\
\hline Elastomer-LP980 & $4.5: 1$ & 80.8 & 89.7 & 60.5 & -34.3 & 0.84 & 334 & 29 \\
\hline Elastomer-LP2 & $7.2: 1$ & 87.8 & 92.0 & 63.0 & -39.5 & 0.74 & 126 & 35 \\
\hline Elastomer-LP32 & $7.2: 1$ & 88.2 & 90.2 & 71.3 & -39.4 & 0.76 & 261 & 30 \\
\hline Elastomer-LP55 & $7.2: 1$ & 87.4 & 87.4 & 74.8 & -38.3 & 0.76 & 412 & 22 \\
\hline
\end{tabular}

*calculated from the S-elemental analysis of the obtained elastomers. 
vinyl groups with thiols. From Table 2, it can be concluded that the gel fraction increased with crosslinking agent increased, and the chain length of PSF oligomers had little effect on gel fractions of corresponding elastomers. As controlled, the gel fractions of the polysulfide elastomers cured by $\mathrm{MnO}_{2}$ (one of widely-used metal oxide curing agents for PSF oligomers) were also investigated under the same experiment conditions. The results reveal that, as for the same type of PSF oligomer, the elastomers cured by $\mathrm{MnO}_{2}$ had somewhat lower gel fraction and higher swelling ratio than those cured by bisphenolA diacrylate resin. The reason is that some plasticizers have to be employed with metal oxides to make up curing agents, which would be extracted by solvents.

\subsection{Mechanical and thermal properties}

The stress-strain curves of polysulfide-based elastomers are shown in Figure 5, and the results are summarized in Table 2. Usually, the tensile strength of polysulfide polymer without reinforce is relatively poor due to lower molecular interaction [23]. From Figure 5a, comparison of elastomers prepared from PSF oligomers with the same cross-linking agent, Elastomer-LP3, Elastomoer-LP23, ElastomerLP2, shows a simultaneously higher tensile strength and ultimate elongation for lower molecular weight PSF based elastomer (Elastomer-LP3), and comparing the tensile tests of Elastomer-LP980 and Elas-

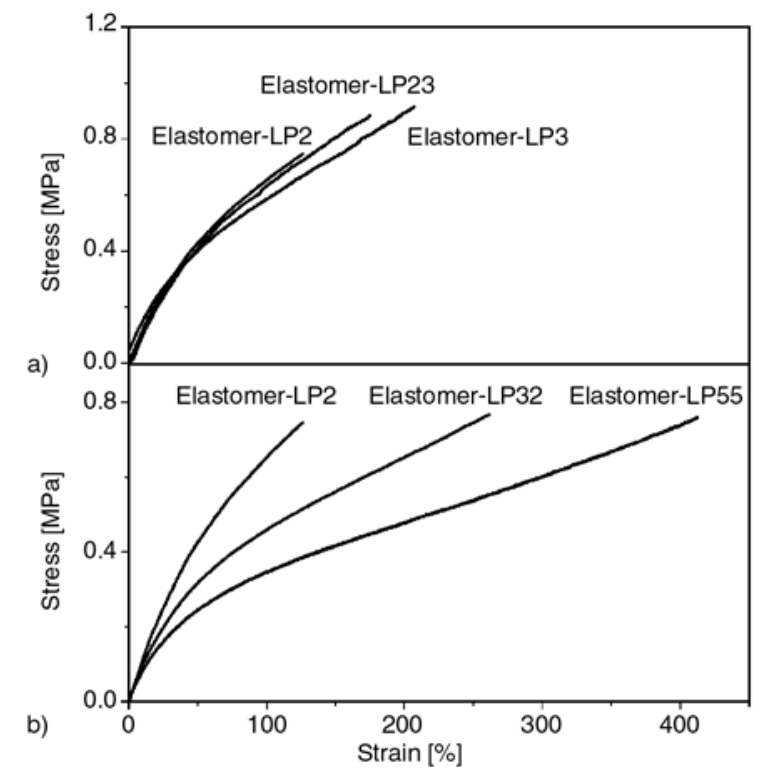

Figure 5. Strain-stress curves of polysulfide-based elastomers: Elastomer-LP3, LP23, LP2 (a) and LP55, LP32, LP2 (b)
tomer-LP32 gives similar results. The results reveal that incorporation of the bisphenol-A structure imparted improved elongation and tensile strength for elastomers, for bisphenol-A unit acts as physical cross-linking point. This effect also has been found in high-energy-absorbing thio-ene and thiol-eneacrylate mixture [11]. On the other hand, with the same molecular weight of PSF oligomers, the ultimate elongation increases significantly from Elastomer-LP2, Elastomoer-LP32 to Elastomer-LP55 (Figure 5b) as well as from Elastomer-LP23 to Elastomer-LP980, but the tensile strength does not have obvious change due to the same dosage of bisphenol-A diacrylate employed. This effect of branching on physical properties of polysulfide elastomer is similar as that of metal oxide cured polysulfide polymer.

Thermal stability of the polysulfide-based elastomers was characterized by thermogravimetric analysis (shown in Figure 6). Usually, the thermal stability of polysulfide polymers depends on the composition of the material backbone as well as the curing agent employed to vulcanize the PSF oligomer. As observed from in Figure 6, all of the obtained polysulfide elastomers are thermally stable with $5 \%$ weight loss at temperatures around $290^{\circ} \mathrm{C}$ despite of different dosage of bisphenol-A diacrylate resin used, indicating higher thermal stability of bisphenol-A diacrylate structure than polysulfide units. These results can be explained by the presence of the $\mathrm{C}-\mathrm{O}$ bond, more stable at high temperature than an $\mathrm{S}-\mathrm{S}$ or $\mathrm{C}-\mathrm{S}$ bond as indicated by the enthalpy of dissociation [29]. However, as a comparison, polysulfide elastomer cured by $\mathrm{MnO}_{2}$ displayed $5 \%$ weight loss at temperature of $216^{\circ} \mathrm{C}$. The results verify that, apart from an acid-catalyzed hydrolytic attack on the formal group in polysulfide

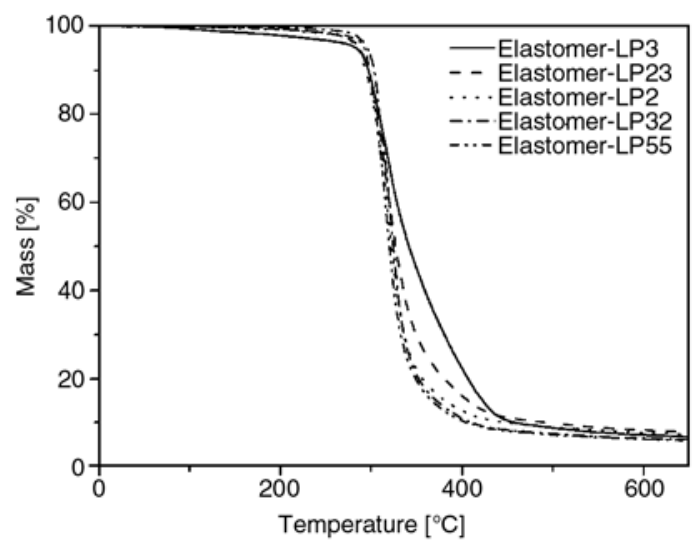

Figure 6. TGA curves of polysulfide-based elastomers 
backbone, another source of thermal instability arises due to metal incorporation in polysulfide from the reaction of mercaptan with metal oxides $[23,30]$.

Figure 7 and Figure 8 show dynamic mechanical properties of elastomers synthesized from different liquid polysulfide oligomers as a function of molecular weight and cross-linking agent respectively, and the data of the glass transition temperatures $\left(T_{\mathrm{g}}\right)$ are outlined in Table 2. It can be seen from Figure 7 and Figure 8, all of the $\tan \delta$ versus temperature plots exhibited one single sharp peak, which indicated the formation of a homogeneous polymer

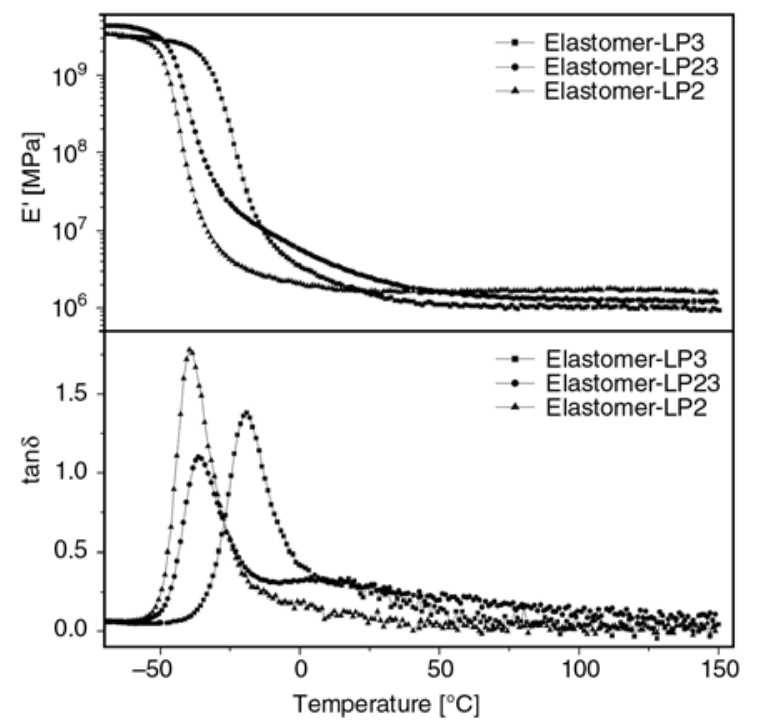

Figure 7. Dynamic mechanical properties of elastomers synthesized from different liquid polysulfide oligomers as a function of molecular weight

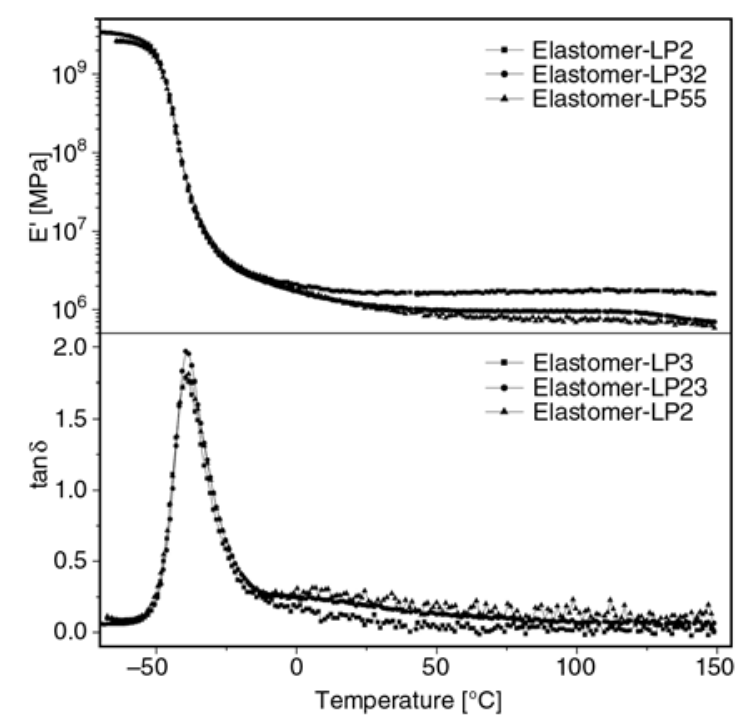

Figure 8. Dynamic mechanical properties of elastomers synthesized from different liquid polysulfide oligomers as a function of cross-linking agent work. The $T_{\mathrm{g}}$ of the samples was around $-34 \sim-39^{\circ} \mathrm{C}$ except for Elastomer-LP3, which had a higher $T_{\mathrm{g}}$ of $-19^{\circ} \mathrm{C}$. This was due to the characteristic step-growth process of thio-ene addition reaction, as well as the good compatibility of polysulfide and bisphenol-A structure. Bisphenol-A units gave a large number of domains dispersing in the soft-segment matrix (polysulfide), which resulted in higher $T_{\mathrm{g}}$. However, the cross-linking agent of PSF monomers also had little effect on $T_{\mathrm{g}}$ of corresponding elastomers [23]. Another point to note is that all elastomers showed good high-temperature properties, the storage modulus $\left(E^{\prime}\right)$ almost held the line between $50 \sim 150^{\circ} \mathrm{C}$, and the greater the cross linking agent, the higher is $E^{\prime}$.

\section{Conclusions}

Polysulfide-based elastomers were successfully prepared through a simple one-pot thiol-Michael addition of the liquid polysulfide oligomers with bisphenol-A diacrylate resin. High mercaptan functional group conversion was achieved despite of different molecular weight of the liquid polysulfide oligomers. After avoiding mercaptide from the reaction of mercaptan with metal oxide, the obtained elastomers having $-\mathrm{C}-\mathrm{C}$ - cross-linkage exhibited higher thermal stability than metal oxide cured polysulfide polymer. At the same time, the elastomers continued to keep low temperature flexibility of polysulfide polymer except Elastomer-LP3, which was due to higher content of bisphenol-A structure. All the tensile strength of the samples was comparable to that of polysulfide polymer cured by metal oxide. Moreover, the elongation of the samples could be expediently controlled by adjusting the cross-linking agent or mercaptan fraction of liquid polysulfide oligomer employed. This simplicity and efficiency of the reported procedure provides a fast and green approach (without metal oxides and plasticizers) for preparing polysulfide elastomers, and tailing their physical properties to meet a potential wide range of application.

\section{References}

[1] Hoyle C. E., Bowman C. N.: Thiol-ene click chemistry. Angewandte Chemie International Edition, 49, 1540-1573 (2010).

DOI: 10.1002/anie.200903924

[2] Kade M. J., Burke D. J., Hawker C. J.: The power of thiol-ene chemistry. Journal of Polymer Science Part A: Polymer Chemistry, 48, 743-750 (2010). DOI: $10.1002 /$ pola.23824 
[3] Dondoni A.: The emergence of thiol-ene coupling as a click process for materials and bioorganic chemistry. Angewandte Chemie International Edition, 47, 89958997 (2008). DOI: $10.1002 /$ anie. 200802516

[4] Kempe K., Krieg A., Becer C. R., Schubert U. S.: 'Clicking' on/with polymers: A rapidly expanding field for the straightforward preparation of novel macromolecular architectures. Chemical Society Reviews, 42, 176-191 (2012). DOI: $10.1039 / \mathrm{c} 1 \mathrm{cs} 15107 \mathrm{j}$

[5] Khire V. S., Yi Y., Clark N. A., Bowman C. N.: Formation and surface modification of nanopatterned thiolene substrates using step and flash imprint lithography. Advanced Materials, 20, 3308-3313 (2008). DOI: $10.1002 / \mathrm{adma} .200800672$

[6] Khire V. S., Kloxin A. M., Couch C. L., Anseth K. S., Bowman C. N.: Synthesis, characterization and cleavage of linear polymers attached to silica nanoparticles formed using thiol-acrylate conjugate addition reactions. Journal of Polymer Science Part A: Polymer Chemistry, 46, 6896-6906 (2008).

DOI: $10.1002 /$ pola.22999

[7] Gress A., Völkel A., Schlaad H.: Thio-click modification of poly[2-(3-butenyl)-2-oxazoline]. Macromolecules, 40, 7928-7933 (2007).

DOI: $10.1021 / \mathrm{ma} 071357 \mathrm{r}$

[8] Sengupta S. S., Parent J. S., McLean J. K.: Radicalmediated modification of polypropylene: Selective grafting via polyallyl coagents. Journal of Polymer Science Part A: Polymer Chemistry, 43, 4882-4893 (2005).

DOI: $10.1002 /$ pola.20952

[9] Keleş E., Hazer B., Cömert F. B.: Synthesis of antibacterial amphiphilic elastomer based on polystyreneblock-polyisoprene-block-polystyrene via thiol-ene addition. Materials Science and Engineering C, 33, 1061-1066 (2013).

DOI: $10.1016 /$ j.msec.2012.11.029

[10] Campos L. M., Meinel I., Guino R. G., Schierhorn M., Gupta N., Stucky G. D., Hawker C. J.: Highly versatile and robust materials for soft imprint lithography based on thiol-ene click chemistry. Advanced Materials, 20, 3728-3733 (2008).

DOI: 10.1002/adma.200800330

[11] Senyurt A. F., Wei H., Hoyle C. E., Piland S. G., Gould T. E.: Ternary thiol-ene/acrylate photopolymers: Effect of acrylate structure on mechanical properties. Macromolecules, 40, 4901-4909 (2007).

DOI: $10.1021 / \mathrm{ma} 062534 \mathrm{~b}$

[12] Wei H., Senyurt A. F., Jönsson S., Hoyle C. E.: Photopolymerization of ternary thiol-ene/acrylate systems: Film and network properties. Journal of Polymer Science Part A: Polymer Chemistry, 45, 822-829 (2007). DOI: $10.1002 /$ pola.21844
[13] Niu G., Zhang H., Song L., Cui X., Cao H., Zheng Y., Zhu S., Yang Z., Yang H.: Thiol/acrylate-modified PEO-PPO-PEO triblocks used as reactive and thermosensitive copolymers. Biomacromolecules, 9, 26212628 (2008).

DOI: $10.1021 / \mathrm{bm} 800573 \mathrm{e}$

[14] Zheng H., Li Y., Zhou C., Li Y., Yang W., Zhou W., Zuo Z., Liu H.: Synthesis of a [2]rotaxane incorporating a 'magic sulfur ring' by the thiol-ene click reaction. Chemistry A: European Journal, 17, 2160-2167 (2011). DOI: $10.1002 /$ chem. 201002964

[15] Fairbanks B. D., Schwartz M. P., Halevi A. E., Nuttelman C. R., Bowman C. N., Anseth K. S.: A versatile synthetic extracellular matrix mimic via thiol-norbornene photopolymerization. Advanced Materials, 21, 50055010 (2009). DOI: $10.1002 /$ adma.200901808

[16] Flores J. D., Treat N. J., York A. W., McCormick C. L.: Facile, modular transformations of RAFT block copolymers via sequential isocyanate and thiol-ene reactions. Polymer Chemistry, 2, 1976-1985 (2011). DOI: $10.1039 / \mathrm{c} 1$ py00182e

[17] Pounder R. J., Stanford M. J., Brooks P., Richards S. P., Dove A. P.: Metal free thiol-maleimide 'Click' reaction as a mild functionalisation strategy for degradable polymers. Chemical Communications, 2008, 51585160 (2008). DOI: $10.1039 / \mathrm{b} 809167 \mathrm{f}$

[18] Simpson N., Takwa M., Hult K., Johansson M., Martinelle M., Malmström E.: Thiol-functionalized poly $(\omega-$ pentadecalactone) telechelics for semicrystalline polymer networks. Macromolecules, 41, 3613-3619 (2008). DOI: $10.1021 / \mathrm{ma} 702419 \mathrm{~m}$

[19] Takwa M., Hult K., Martinelle M.: Single-step, solvent-free enzymatic route to $\alpha, \omega$-functionalized polypentadecalactone macromonomers. Macromolecules, 41, 5230-5236 (2008).

DOI: $10.1021 / \mathrm{ma} 800074 \mathrm{a}$

[20] Carioscia J. A., Lu H., Stanbury J. W., Bowman C. N.: Thiol-ene oligomers as dental restorative materials. Dental Materials, 21, 1137-1143 (2005).

DOI: $10.1016 /$ j.dental.2005.04.002

[21] Clark T., Kwisnek L., Hoyle C. E., Nazarenko S.: Photopolymerization of thiol-ene systems based on oligomeric thiols. Journal of Polymer Science Part A: Polymer Chemistry, 47, 14-24 (2009).

DOI: $10.1002 /$ pola.23089

[22] Li Q., Zhou H., Wicks D. A., Hoyle C. E.: Thiourethane-based thiol-ene high $T_{\mathrm{g}}$ networks: Preparation, thermal, mechanical, and physical properties. Journal of Polymer Science Part A: Polymer Chemistry, 45, 5103-5111 (2007).

DOI: $10.1002 /$ pola.22252

[23] Usmani A. M.: Chemistry and technology of polysulfide sealants. Polymer-Plastics Technology and Engineering, 19, 165-199 (1982).

DOI: $10.1080 / 03602558208067730$ 
[24] Dong W., Quan Y., Zhang J., Chen Q.: The structural and mechanical properties of polysulfide-based polyurea. Polymer International, 52, 1925-1929 (2003). DOI: $10.1002 /$ pi.1301

[25] Quan Y., He P., Zhou B., Chen Q.: Modification of polysulfide sealant with polysulfide polythio-urethane-urea. Journal of Applied Polymer Science, 106, 2599-2604 (2007).

DOI: 10.1002/app.26792

[26] Zhang J., Wang Z., Ding G., Quan Y., Chen Q.: The effect of epoxy resin to reduce the compression set of polysulfide sealant. Journal of Applied Polymer Science, 125, 390-395 (2012).

DOI: $10.1002 / a p p .35651$

[27] Zhou B., Shen M., Wang Q., Chen Q.: Kinetic study of polysulfide-acrylate click reaction by DEA and DMA. Polymers for Advanced Technologies, 21, 1-8 (2011). DOI: $10.1002 /$ pat. 1773
[28] Hoyle C. E., Lee T. Y., Roper T.: Thiol-enes: Chemistry of the past with promise for the future. Journal of Polymer Science Part A: Polymer Chemistry, 42, 53015338 (2004). DOI: $10.1002 /$ pola.20366

[29] Soeriyadi A. H., Li G-Z., Slavin S., Jones M. W., Amos C. M., Becer C. R., Whittaker M. R., Haddleton D. M., Boyer C., Davis T. P.: Synthesis and modification of thermoresponsive poly(oligo(ethylene glycol) methacrylate) via catalytic chain transfer polymerization and thiol-ene Michael addition. Polymer Chemistry, 2, 815-822 (2011).

DOI: $10.1039 / \mathrm{c} 0 \mathrm{py} 00372 \mathrm{~g}$

[30] Radharkrishnan T. S., Rao M. R.: Characterization of cured polysulfide polymers by thermal degradation: Pyrolysis-GC and thermogravimetric studies. Journal of Applied Polymer Science, 34, 1985-1996 (1987). DOI: 10.1002/app.1987.070340517 